\title{
$\Psi$ Shape Slotted Wearable Microstrip Patch Antenna for Dual Band
}

\author{
Abdul Mannan \\ M Tech. Scholar \\ ECE Department \\ DIT, Dehradun
}

\author{
Dinesh Kumar \\ Saxena \\ Professor \\ DIT, Dehradun
}

\author{
Prachi Gupta \\ M Tech. Scholar \\ ECE Department \\ DIT, Dehradun
}

\author{
Manish Jaiswal \\ M Tech. Scholar \\ ECE Department \\ DIT, Dehradun
}

\begin{abstract}
This paper presents a $\Psi$ shape slotted wearable probe fed microstrip patch antenna for dual band. In this paper a new design of antenna that resonates at $3.39 \mathrm{GHz}$ with the bandwidth of $139 \mathrm{MHz}$ and also resonates at $4.87 \mathrm{GHz}$ with the bandwidth of $251 \mathrm{MHz}$ is presented. The simulated results along with the different parameters like radiation pattern, VSWR etc. are presented and discussed in this letter. The design and performance of antennas are carried out using HFSS 14.0 software. Main objective of this paper is to achieve the multiple resonances within the same antenna at desired frequencies so that this could be applicable in $\mathrm{S}$ and $\mathrm{C}$ band applications using polyester cloth as a substrate.
\end{abstract}

\section{Keywords}

Microstrip Patch Antenna, Reflection Coefficient, HFSS (High Frequency Structure Simulator).

\section{INTRODUCTION}

With the rapid growth of wireless technology, wireless users hope the speed and service they have from wired connections such as internet access. Future trend in wireless communication is higher data rate or system capacity. To meet the requirement of future application, improvement in the quality of wireless link is essential. Wearable antennas have drawn more and more attention in recent years as they can be integrated into human clothing.

In medical applications, biomedical smart clothing with multiple sensors have been introduced, such as VTAMN (France) which has been integrated with a breath rate, temperature and fall/shock biosensor with GSM/GPRS module into the clothes. WEALTHY (Europe) clothes have also been developed to monitor patient activity, to ensure safety and provide reassurance. Life Shirt (USA), a washable smart textile which includes EEG, ECG and blood pressure sensors, is built for cough and respiration monitoring. For military applications, a fiber-optic sensor has been integrated into soldier uniform to detect various hazards such as chemical, biological and thermal ones $[1,2]$.

Wearable antennas need to be flexible, hidden and light weight, considering the convenience of the user. Therefore textile wearable antennas have become the focus of many antenna research efforts due to their flexibility, durability, and suitability for a wide range of applications such as objects surveillance, wireless medical applications or wireless communication.
Different textile/cloth based materials are used to manufacture these antennas such as cotton, fleece fabric, foam, Nomex, nylon, polyester, conducting ribbon, insulated wire, conducting paint, copper coated fibric, geo textile etc. In literature, different wearable antennas have been reported [3]-[7]. These antennas have been fabricated on the various textile substrates for body centric communication systems that covers Wi-Fi, Wi-Max, WLAN, HYPER LAN, BAN, Bluetooth applications[8].

In this letter, a slotted antenna is proposed which is capable of dual band frequency operation for $3.39 \mathrm{GHz}$ and $4,87 \mathrm{GHz}$ applications. The design and performance of antenna are carried out using HFSS 14.0 software.

The rest of the paper is organized as follows: section two present the antenna structure and design. In section three, simulated result are discussed. The paper finishes with the conclusion in section four.

\section{ANTENNA STRUCTURE AND DESIGN}

The design of antenna 1is shown in figure 1 . The rectangular patch has dimension of $30 \mathrm{~mm} \times 20 \mathrm{~mm}$. The dielectric material selected for this design is polyester cloth with dielectric constant $\left(\epsilon_{\mathrm{r}}\right)=1.39$ and substrate height $(h)=3.14$ $\mathrm{mm}[8]$. The patch antenna is coaxially probe fed at $(2.5,-4.5)$.

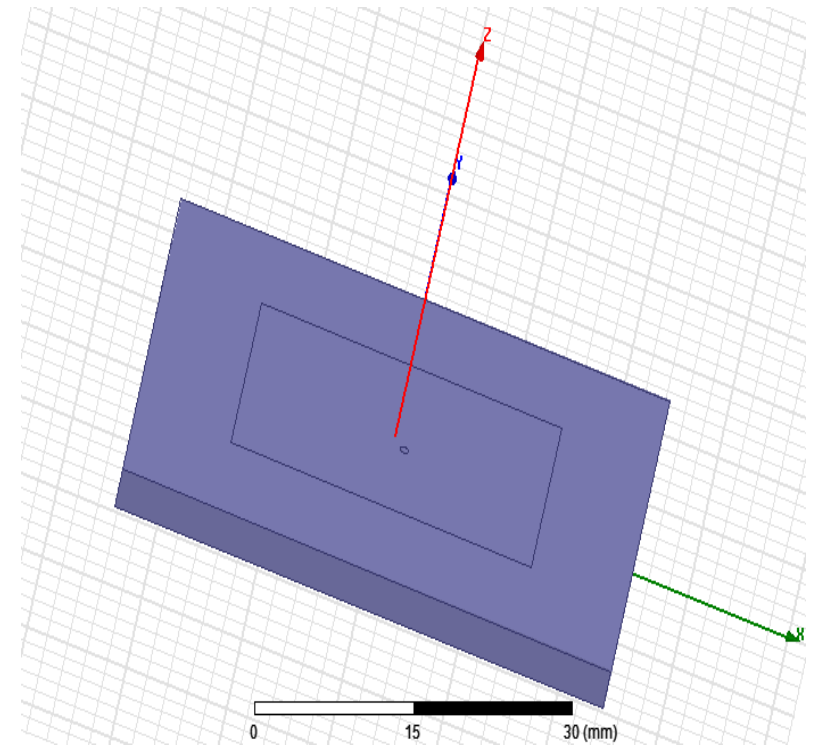

Fig 1: Antenna 1 design 
Figure 2 shows design of antenna 2 which is designed with a sams substrate. All the dimension and position of feed is same as that of antenna1. In this design, slots are created on the rectangular patch at proper position and shape of slot becomes $\Psi$ shaped as this slotting technique produces dual band and antenna resonates at $3.39 \mathrm{GHz}$ and $4.87 \mathrm{GHz}$.

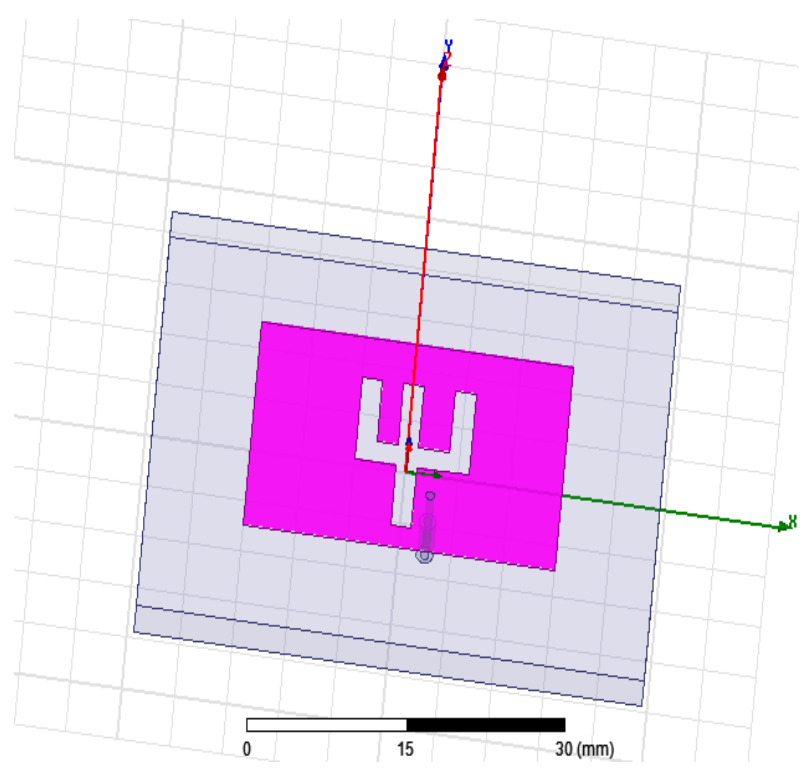

Fig 2 : Antenna2 design.

Table1. Parameters

\begin{tabular}{|l|l|l|}
\hline Parameters & $\begin{array}{l}\text { Antenna1 } \\
\text { In (mm) }\end{array}$ & $\begin{array}{l}\text { Antenna2 } \\
(\mathrm{mm})\end{array}$ \\
\hline Length(ground) & 48.84 & 48.84 \\
\hline Width(ground) & 38.84 & 38.84 \\
\hline Length(patch) & 30 & 30 \\
\hline Width(patch) & 20 & 20 \\
\hline Feed & $(2.5,-4.5)$ & $(2.5,-4.5)$ \\
\hline Substrate Thickness & 3.14 & 3.14 \\
\hline
\end{tabular}

\section{SIMULATION RESULT}

The simulation is done using Ansoft HFSS (14.0). Different parameters like radiation pattern, Reflection coefficient $S_{11}$, VSWR is discussed given below.

\subsection{Radiation Pattern}

The radiation patterns of antenna 2 design are shown below. As the antenna 2 resonates at two frequencies $3.39 \mathrm{GHz}$ and $4.87 \mathrm{GHz}$, the radiation patterns at two different frequencies are shown at different angles of phi $0^{\circ}$ and $90^{\circ}$ in figure 3 .

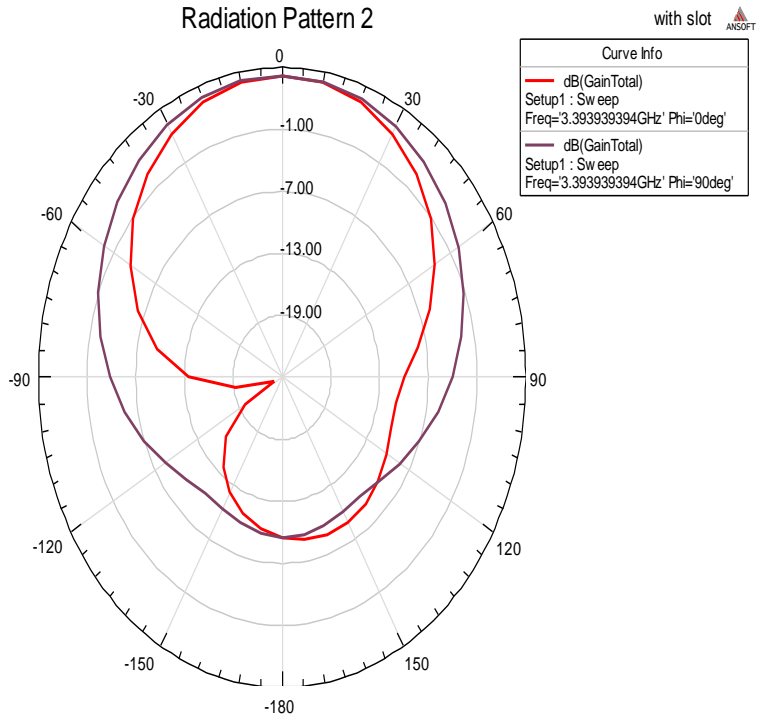

(a)

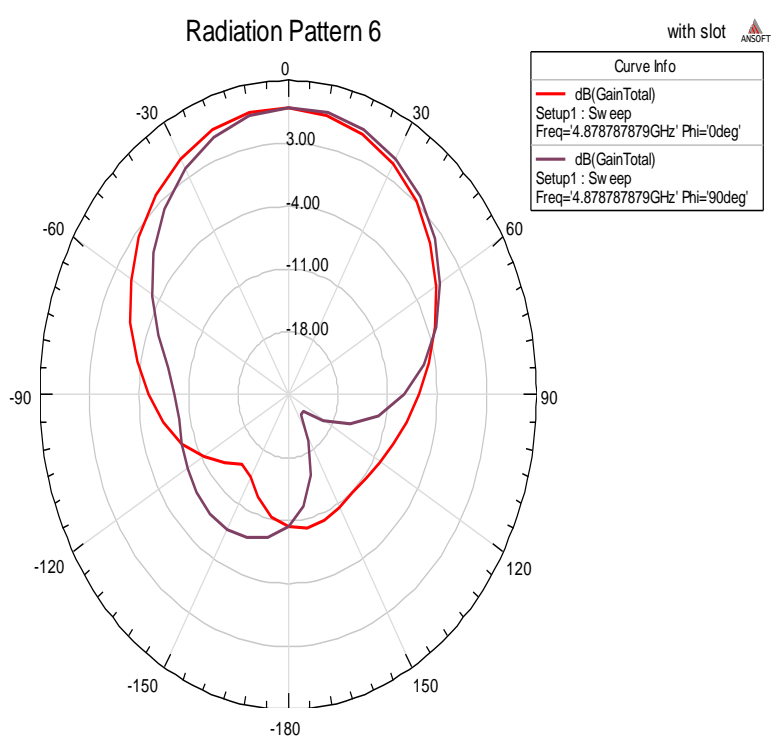

(b)

Fig 3:Radiation pattern of antenna 2 (a) freq. 3.39GHz (b) freq. $4.87 \mathrm{GHz}$

\subsection{Reflection Coefficient}

The slots on the patch are responsible for dual band operation as the slots perturbation on the patch changes the current distribution. The design of antenna 2 shows simulated reflection coefficient obtained at $-26.39 \mathrm{~dB}$ and $-25.85 \mathrm{~dB}$ that resonate at two frequencies $3.39 \mathrm{GHz}$ and $4.87 \mathrm{GHz}$ respectively as shown in figure 4 . 


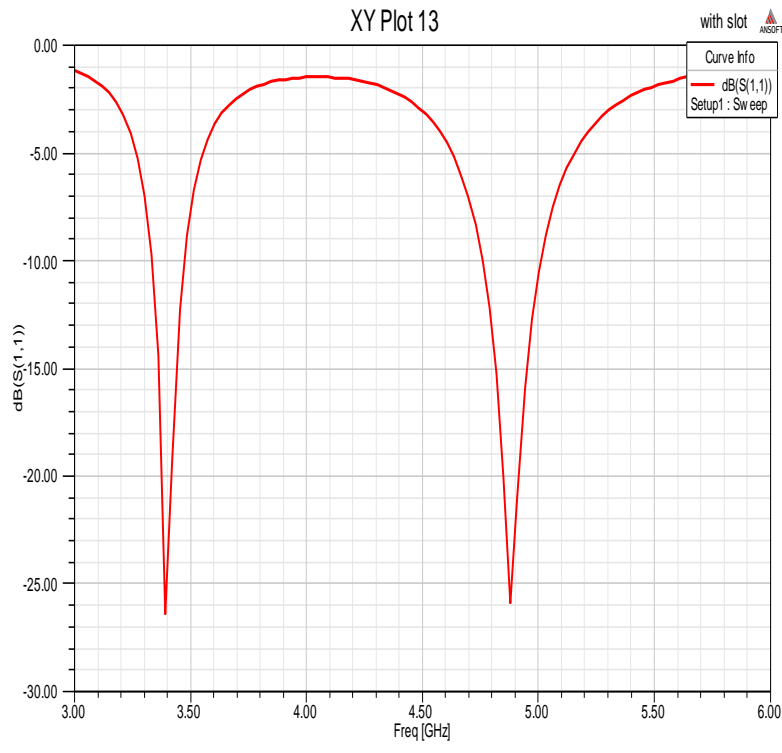

Fig 4: Antenna2

\subsection{Voltage Standing Wave Ratio}

Voltage standing wave ratio of antenna at their resonant frequencies shows the values which are less than 2 that are acceptable as shown in figure 5.

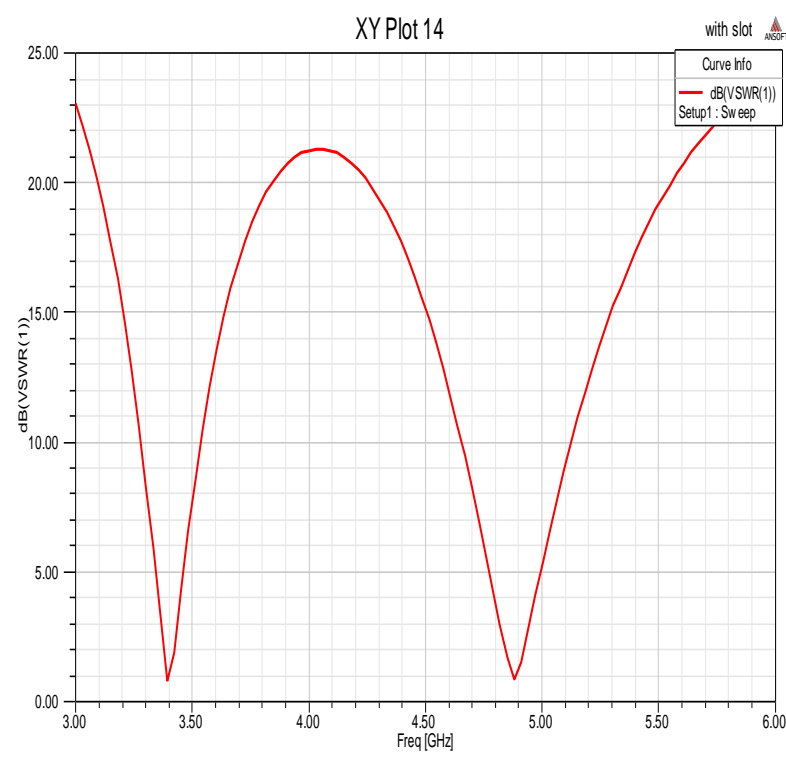

Fig 5: Antenna2

\section{CONCLUSION}

A new design of dual band wearable microstrip patch antenna is presented in this paper using polyester cloth as a substrate. A slotted $\Psi$ shaped microstrip patch antenna fed by co-axial probe has been proposed in this paper. Also slot of $\Psi$ shaped reduces the size of patch to some extent that leads to light weight and easily wearable. The proposed antenna2 is suitable for WiMAX and multi-frequency applications of wireless communication in $\mathrm{S}$ and $\mathrm{C}$ band as the design resonates at frequencies 3.39 and $4.87 \mathrm{GHz}$ that shows its dual band operation. Different parameters are taken along with the radiation pattern.

\section{ACKNOWLEDGEMENTS}

We are extremely grateful to the department of ECE and AEI for their support and encouragement, Dehradun Institute of Technology, Dehradun, India.

\section{REFERENCES}

[1] Mohd E. Jalil, Mohamad K. A. Rahi, Noor A. Samsuri, Noor A. Murad, Huda A. Majid, KamiliaKamardin, and Muhamad A. Abdullah "Fractal Koch Multiband Textile Antenna Performance with Bending, Wet conditions and on the Human Body" Progress In Electromagnetics Research, Vol. 140, 633-652, 2013.

[2] Axisa, F., P. M. Schmitt, C. Gehin, G. Delhomme, E. McAdams, and A. Dittmar, $\mid$ Flexible technologies and smart clothing for citizen medicine, home healthcare, and disease prevention," IEEE Transactions on Information Technology in Biomedicine, Vol. 9,No. 3, 325-336, Sep. 2005.

[3] P. S. Hall and Y. Hao, "Antennas and propagation for body centric communications," Proceedings of First European Conference onAntennas and Propagation (EuCAP 2006), 2006 (Invited Paper)

[4] ArnautDierck and HendrikRogier, "A wearable active antenna for global positioning system and satellite phone,"IEEE Trans. Antennas and Propaga., vol. 61, no.2, pp.532-538, February 2013

[5] J.G.Joshi, Shyam S. Pattnaik, and S. Devi,“Geotextile based metamaterial loaded wearable microstrip patch antenna,'Intl. J Micro.andOptl.Techn., vol.8, no.1, pp. 25-33, 2013

[6] J.G.Joshi, Shyam S. Pattnaik, and S. Devi, "Metamaterial embedded wearable rectangular microstrip patch antenna,"Intl. J of Antennas and Propag., Special issue on Wearable Antennas and Systems,Hindwai Publication Corporation, ID. 974315, pp.1-9, doi:10:1155/2012/974315, 2012

[7] J.G. Joshi andShyam S. Pattnaik "Metamaterial based wearable microstrip patch antennas," Book title: "Handbook of Research on Wireless Communications and Networking-Theory and Practice," Chapter 20, Information Science Reference (an imprint of IGI Global), USA, pp.518-556, DOI: 10.4018/978-1-46665170-8, ISBN 13:9781466651708, February 2014.

[8] J.G.Joshi, Shyam S. Pattnaik, "Dual Band Wearable Microstrip Patch Antenna".

[9] Gehan Sami, Mahmood Mohanna, Mohamed L.Rabeh, “ Tri-band microstrip antenna design for wireless communication application".

[10] Sachin Saurabh, HaneetRana, Shalini Shah, Sudhakar Srivastava,"Multiband Microstrip Antenna with Perturbations for Wireless Communication". 